\title{
THE NUFFIELD FOUNDATION
}

\author{
REPORT FOR 1957-58
}

$\mathrm{I}^{\mathrm{N}}$ $\mathrm{N}$ its thirteenth annual report, covering the year ended March 31, 1958, the Nuffield Foundation records that, of the $£ 8.5$ million distributed during the fifteen years of its existence, about $£ 6.5$ million has been expended on ventures within the United

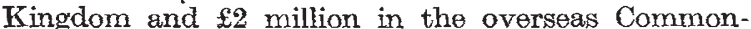
wealth, of which grants totalling $£ 850,000$ were allocated in the year covered by the report. Of this total, about $£ 1.75$ million has been in the fields of science and technology, about $£ 1.5$ million in that of medicine, more than $£ 1$ million on the care of old people and research in aging, and about $£ 1.25$ million on social research and experiment and education. The present report places more emphasis than usual on the Foundation's interest in ventures designed to discover the facts relevant to human behaviour and relationships, and an outstanding illustration of this is the investigation into techniques of sampling and questioning which has been in progress since 1949 under Prof. M. G. Kendall at the London School of Economics. The Foundation has now made a grant of $£ 35,000$ over five years to enable the Unit to expand its work to include studies of the design of questionnaires, the validation of social inquiries, of interviewer-respondent bias and the motives behind the actual behaviour of people.

During the year the Foundation sought the views of leading biologists on the emphasis of its biological policy at a week-end conference at Tunbridge Wells, and the Foundation afterwards decided that biology should remain a major interest, not only because biological research is making its expected contributions to medicine and agriculture, but also because it is indicating the growing points in other disciplines, particularly chemistry. Accordingly, the Foundation will support work which promises to lead to a new understanding of biological processes, and the report refers particularly to the Foundation's interest in new developments in the analysis of synthetic systems, the control of enzymic synthesis, and the sequence of events that link particular nuclear components with the organization of the cell. In psychiatry it is interested in studies of behaviour and learning that throw light on the mechanisms involved, and it will continue to be interested in instrumentation, both for resolving existing biological processes and for the possible development of new techniques.

In accordance with this policy, a major grant of the year was $£ 34,000$ for the construction of an analogue computer at University College, London, resembling the nervous system of an animal, which will be trained to recognize shapes held in front of its model eye. The new computer, which is the outcome of Prof. J. Z. Young's work on the physiology of learning, should be able to simulate the learning of the alphabet and the numerals and a limited number of more complex shapes, which might include human faces. The Institute of Experimental Psychology, University of Oxford, has also received a grant of $£ 10,000$ over three years and nine months towards Dr. N. S. Sutherland's investigation of the mechanisms by which animals and human beings analyse stimuli and, in particular, how visual shapes are analysed. Two grants of $£ 1,980$ over three years and
$£ 900$ over three years were made for investigations at the University of Reading on the structure of optic ganglia of the locust and their connexions and on the brain of the wood ant. A grant of $£ 2,800$ over two years was made towards Dr. K. E. Machin's work on physical aspects of behaviour, and a grant of $£ 1,500$ a year for two years to University College, London, was in support of three studies which are part of general research into the causes and treatment of mental deficiency: the search for rare or hitherto unknown cases of metabolic disturbance ; dietetic experiments with selected amino-acids in cases of metabolic anomaly; and clinical trials of biologically active substances.

A grant of $£ 15,000$ over five years was made in support of Prof. B. Katz's work at University College, London, on nerve cells and muscle fibres, and further support of up to $£ 1,500$ a year for three years is being provided for Prof. J. Baddiley's work at King's College, Newcastle upon Tyne, on the chemical structure of bacterial cell walls. A programme of research into the effects of radioactive fall-out on wild animal population being undertaken by St. Bartholomew's Hospital Medical College is being supported by a grant of $£ 3,200$. A grant of $£ 4,884$ over three years was offered for a study of hybrid vigour at University College, London, and $£ 800$ a year for two years towards one of the acetate metabolism by Chlorella.

Towards Dr. J. D. Biggers's work at the Royal Veterinary College, London, on the growth of embryonic bones on chemically defined media, a grant of $£ 3,200$ over five years was offered, and one of $\mathfrak{2 6 , 0 0 0}$ over three years was made to University College, London, in support of investigations on the mechanisms of processes catalysed by enzymes. For studies of pregnancy toxæmia and scrapie and myopathy in sheep at the Nuffield Institute for Medical Research, Oxford, a renewed grant of $£ 7,500$ for two years was made, and one of $£ 6,500$ over three years for research into the bacteriology of calf diarrhœa at the Royal Veterinary College, London. $£ 12,000$ was offered to the Marine Biological Association of the United Kingdom for the complete reconstruction of its aquarium. $£ 2,200$ a year for five years was given to the British Trust for Ornithology for a centre to collate, analyse and file the pooled data of bird observatories and to prepare reports. Up to $£ 2,350$ over three years was offered to the University of Glasgow for studies on the effects of physical and biological factors on spawning, while two interesting minor grants of $£ 1,000$ were made, one to Marlborough College towards the cost of apparatus needed for actual research into the magnetic susceptibilities of materials, and the other to the University of Leeds for the production of a series of films presenting the development of scientific ideas in a form suitable for sixth forms and undergraduates.

Besides administering the Oliver Bird Fund, the Foundation contributes an equal sum for fundamental and clinical research into the causes and cure of rheumatic diseases. Experience of the past four years points to the need for more centres specializing in rheumatism if more rapid progress is to be made. 
Two problems in giving effect to such a policy are how to attract more clinicians into rheumatology and how to stimulate the interest of the pure scientist in the study of fundamental problems which may bear on rheumatism. Hope is expressed that work will soon begin on the difficult problems of what controls the behaviour of the fibroblast and what are the enzyme systems involved. Of four new grants in this field during the year, three have been given to centres already supported by the Foundation; the fourth, of $£ 4,000$ over two years, was to the Institute of Orthopædics for research on the constituents of cartilage. The controlled clinical trials of cortisone and allied hormones suggest that both prednisone and prednisolone are superior to cortisone in the treatment of rheumatoid arthritis and that there may be some fundamental difference between the action of these two steroids and cortisone. Of other grants for medical research may be mentioned one of $£ 80,000$ to endow a chair in child surgery at the University of London; up to $£ 2,000$ to the University of Leeds towards the cost of acquiring a Skeggs Leonard type of artificial kidney for comparison with the Merrill type; $£ 2,250$ a year for three years and a capital grant of $£ 300$ to the Institute of Neurology, University of London, for a long-term clinical investigation into the effects of hypotensive drugs and anticoagulant therapy in the treatment of cerebrovascular disease; a further grant of $£ 10,700$ over two years to the Tuberculous Meningitis Unit, United Oxford Hospitals, for research on disseminated sclerosis ; up to $£ 12,000$ towards the cost of adapta. tions to the Pioneer Health Centre, Peckham, for a diagnostic centre for local doctors; and $£ 2,520$ a year for three years to the Institute of Psychiatry, University of London, for work on cutting the pituitary stalk.

Among the grants for the care of old people and research in aging are one of $£ 2,500$ to the National
Institute for Adult Education for a comprehensive inquiry into existing educational facilities for the elderly, the use made of them, and the general role of adult education in helping people to adjust themselves to retirement and to continue leading an active life; $£ 3,000$ for a pilot study into the economic circumstances of people over retirement age; $£ 2,000$ over three years to the University of Exeter for an investigation into the effects of aging on the performance of tasks of varying complexity; and a further grant of a five-year fellowship rising from $£ 1,500$ to $£ 1,700$ a year to Dr. A. Comfort for his long-term investigations at University College, London, into the aging of fish and the pattern of aging in dogs and thoroughbred horses, which may yield information on the inheritance of longevity and the effects of parental age.

Other grants for social research and education during the year include: $\mathfrak{f} 6,850$ over three years in support of a study of the social composition of a Lancashire industrial town, which will comprise an analysis of the number and functions of the professional, managerial and administrative groups and their role in the life of the community, and a study of the working-class population and its part in political and associational life and the relation of local to national culture. This study is being conducted by the Department of Social Anthropology and Sociology, University of Manchester.

A brief summary is given of the first part of $\mathbf{M r}$. J. Trenaman's study of the educational possibilities of radio and television, newspapers and films, towards which a further grant of $£ 500$ has been made. Broadcasting and the Press are the only contemporary influences that can reach across a majority of the population to the fringes of the 45 per cent that are resistant to education in its broader sense, and $\mathrm{Mr}$. Trenaman thinks they could do more to stimulate critical thinking.

\section{SCIENTIFIC BASIS OF LAND PLANNING IN THE TROPICS}

\begin{abstract}
$\mathrm{A}^{\mathrm{x}}$ $\mathrm{N}$ inescapable problem of the present-day world is the increasing pressure of population on land resources. Widespread knowledge and practice of death eontrol have overtaken birth control so that, one by one, the countries of the world are experiencing the problem of how to match expanding population with expanding food production. The problem has now hit the Gambia, and in facing it the Gambian Government, perhaps influenced by the salutary lesson of the failure of the poultry scheme, is wisely realizing the fundamental need for a basis of factual knowledge on which to plan its land use and land planning policy. Rather more than a hundred and fifty years ago Britain, faced with the imminent possibility of a Napoleonic invasion, realized the need for adequate maps and set up the Ordnance Survey.

To-day, the far-flung parts of the Commonwealth face crises of many different types, and the Directorate of Overseas Surveys has been charged with the Herculean task of providing at least a skeleton map cover as a basis of operations. The maps the Directorate is producing are for the most part on a scale of $I: 50,000$ and are based essentially on air
\end{abstract}

photographs. At the same time, the air photographic cover provides a wealth of other information, notably that of present land use. There are special reasons for using this information to prepare a series of land use maps* of the Gambia on the scale of $1: 25,000$. The sandy Ieached soils in the past have been worked on a system of bush fallowing but produce only indifferent crops of sorghum, millet with some cassava and maize and groundnuts as a cash crop, and a little upland rice. With increased population the period of fallow is so shortened that the soils do not recover and the system breaks down. With Government aid, attention has been turned to the clearance of mangrove and grass swamps bordering the Gambia River and the cultivation of their heavy clay soils for rice. This is more revolutionary than it sounds, because, traditionally, the women have cultivated the land; but swamp clearance, construction of bunds and causeways and mechanized

* Directorate of Overseas Surveys. Gambia Land Use Map, Sheet 12/1 : Janneh Kunda. Gambia Land Use Map, Sheet 14/11 : Mansa Konko. (Scale 1:25,000.) (Tolworth: Directorate of Overseas Surveys, 1958. Obtainable from Edward Stanford, Ltd., 12 Long Acre, London, 